\title{
An Application of BBNs on the Integrated Energy Efficiency of Ship- Port Interface: A Dry Bulk Shipping Case
}

Onder Canbulat ${ }^{\mathrm{a} *}$, Murat Aymelek $^{\mathrm{b}, \mathrm{c}}$, Osman Turan ${ }^{\mathrm{a}}$ and Evangelos Boulougouris $^{\mathrm{a}, \mathrm{d}}$

${ }^{a}$ Department of Naval Architecture, Ocean, and Marine Engineering, Faculty of Engineering, University of Strathclyde, Glasgow, United Kingdom; ${ }^{b}$ Socio-Economic Marine Research Unit, Whitaker Institute for Innovation and Societal Change, National University of Ireland, Galway, Ireland; ${ }^{c}$ Department of Marine Engineering, Faculty of Naval Architecture and Maritime, Izmir Katip Celebi University, Izmir, Turkey; ${ }^{d}$ Maritime Safety Research Centre, Department of Naval Architecture, Ocean, and Marine Engineering, Faculty of Engineering, University of Strathclyde, Glasgow, United Kingdom

*corresponding author: trcanbulat@gmail.com

ORCID ID:

O. Canbulat: 0000-0002-9507-9780,

M. Aymelek: 0000-0003-2656-5846

O. Turan: 0000-0003-1877-8462

E. Boulougouris: 0000-0001-5730-007X 


\section{An Application of BBNs on the Integrated Energy Efficiency of Ship- Port Interface: A Dry Bulk Shipping Case}

A considerable amount of energy is consumed with every completed ship voyage and each port operation performed. Recent regulative approaches by the IMO are to enforce the shipping industry to become more energy efficient and sustainable. There is a growing amount of literature on the energy efficiency management of ships and ports. However, there is still inadequate research effort on the ship-port interface in order to obtain an Integrated Energy Efficiency framework for marine transport operations. In this research, a theoretical concept is generated to measure holistic energy efficiency in shipping operations. The main purpose of this paper is to identify nodes of the integrated ship-port energy efficiency framework and develop a probabilistic approach, which can help to increase energy efficiency and reduce $\mathrm{CO} 2$ emissions for shipping companies. This research generates an application of BBNs on ship-port interface regarding the integrated operational energy efficiency interactions by aiming to optimise holistic operational energy efficiency and $\mathrm{CO} 2$ emissions. The outcomes suggest that it would be possible to increase the probability of a more energy efficient and sustainable marine transport operation by integrating the influences of port and ship operation performances and their elements on the related route planning and slow steaming decisionmaking.

Keywords: Integrated marine transport system; shipping energy efficiency management; Bayesian belief networks; dry bulk shipping; ship-port interface 


\section{Introduction}

The marine transport industry has achieved significant evolutions due to its adaptive nature to trends in international trade and its openness to innovation. In this way, the shipping business has been growing continuously and is operated in a more sophisticated, efficient and effective way (Cullinane 2014). In the last decade, energy management and sustainability in marine transport especially have become one of the priorities of ship and port management. The minimisation of the energy consumption by employing cost-effective energy-saving measures, allows shipping to reduce operational expenditures (OPEX) and managerial costs, reduces the negative effects on climate change, and prevents environmental pollution. On the other hand, energy saving measures should not negatively affect the balance sheets of the owners due to delayed deliveries and reduction of annual cargo volume to be transported. Tackling the fleet and portrelated emissions is the trending issue of the maritime industry without hindering the development of waterborne transportation movements and the profitability of the industry (Helfre and Boot 2013).

Marine trade is an energy effective and an environmentally friendly trade mode compared to its alternatives (Johnson 2014). Especially with the entrance of the larger ships into the global shipping market, emissions and energy consumptions per cargo unit transported have been reduced significantly. Furthermore, the global emission share of shipping is predicted to increase between $50 \%$ and $250 \%$ by 2050 (IMO 2014). However, due to the increase in total global emissions and climate change influences, actions need to be taken by all stakeholders. The international characteristics of marine transport help decision-makers and promote strategies at a global scale to deal with sustainability challenges more effectively. IMO has grouped its energy efficiency enforcement strategy in short, mid and long-term categories (MEPC.304 (72)). The first group includes the 
Ship Energy Efficiency Management Plan (SEEMP), Energy Efficiency Design Index (EEDI), and Energy Efficiency Operational Index (EEOI). The Market Based Measurements (MBM) are part of the mid-term candidate measures while the development and provision of zero-carbon or fossil-free fuels are perceived as the longterm measures for the reduction of the GHG emissions.

Mitigation of $\mathrm{CO}_{2}$ emission per tonne-mile is the main aim of EEOI (Lee and Nam 2017). Therefore, in addition to the economic benefits of efficient energy consumption, ship energy efficiency improvements should lead to an ample decrement of $\mathrm{CO}_{2}$ release and mitigate the negative aspects of shipping in regards to global warming.

In consideration of bunker prices, energy expenses represent between $60 \%$ and $70 \%$ of total voyage expenditures of an average cargo ship (Buxton, 1985). When high fuel prices appear in the shipping market, energy efficiency becomes the top priority for a considerable part of ship operators (Rehmatullaa and Smith 2015). Varieties of energy efficiency measures exist in maritime transport practices to ensure that energy usage is maintained at a sophisticated level. These measures comprise of: the appropriate allocation of the vessel capacity, optimal hull design, velocity operating profile, machinery layout (including short and long term performance perspectives); instantaneous power optimisation, speed and draught optimisation; optimal adjustments to propulsion system according to weather and fouling; efficient movement of goods at the ship and within the port, the effective coordination of different activities within the port, information exchange between the various parties. (Plessas et al. 2013; Johnson 2014; McKinnon 2014; Sharma 2014).

Redundant port waiting times are causing unnecessary energy consumption and GHG emissions (Winnes, Styhhre, Fridell 2015). Optimising port times of ships with speed and route planning, as well as measuring the performance of the total marine 
transport operation, including both voyage and port aspects, are attracting interest from the operators. Beside the ship's voyage performance, Virtual Arrival policies have been developed to optimise ship performance at ports in particular to avoid long port and anchoring times, excessive port expenses, and needless energy consumption (Jia et al. 2017). It is well-understood that the port operation performance is also influencing energy consumption, operational costs and $\mathrm{CO}_{2}$ emission of ships significantly (Moon and Woo 2014). From the perspective of ship management, it is essential to reduce the time and energy consumption at ports. On the other hand, in some cases, charterers may require particular delays of a ship's arrival due to their operational and storage reasons. Virtual Arrival is a legal mechanism ensuring ship speed arrangements on a certain route and port, and handling and storage expense minimisation (Ozturk 2013). Some of the shipowners have invested in virtual arrival algorithms and relevant software developments. However, these algorithms have very limited scope and focus mainly on a ship-port interface only due to commercial interests of shipping companies. Therefore, additional developments and enhancements are required in order to consider environmental and energy consumption issues.

During the last decade, research focussed on dependability/inter-operability of marine transport systems including port and ship sub-systems to enhance their reliability, safeness, efficiency and environmental performance (Mansouri et al., 2009). Numerous diverse sets and schemes attempted to emphasise the issues related to the dependability difficulties. Some researchers (Cao, Coutts, and Lui 2013; Haser 2013; Neil, Littlewood, and Fenton 1996; Yuqing and Tong 2008) propose that the BBNs which have been introduced by Thomas Bayes in 18th century, led to the production of the rule that would provide the most suitable method to address the aforementioned challenges. Although BBNs were mainly applied on maritime safety risk, maritime design risk and financial 
risk management. It is possible to adapt it to any probabilistic analysis and measure the performance of a marine transport system. Due to the interoperable nature of marine transport system, BBNs may provide a useful tool to measure the IEE of ships and ports, especially for ships working on liner service, consecutive voyage chartering and time chartering.

The paper focuses on both ship and port primary energy efficiency variables influencing the holistic energy efficiency of marine transport. It presents an integrated method to increase energy effectiveness, enhance cost effectiveness and to mitigate $\mathrm{CO}_{2}$ releases attributable to the activities by vessels and port operations. A holistic course of action is required in order to measure energy efficiency and emission of ships employed in liner services and under consecutive voyage or time charter conditions more comprehensively, by considering both the ship's voyage and port operations. This research proposes a holistic system inter-operability framework that comprises of shore side and vessel operating activities by utilising probability based BBNs. The developed structure in this paper may assist to quantify energy efficiency performance of a particular port in regards to a specific shore based marine transport operation more holistically, considering both ship voyage and port operation aspects.

Following a structured methodological design, this research provides satisfactory information to develop systematic and functional knowledge concerning the application of BBNs in terms of the energy efficiency and $\mathrm{CO}_{2}$ emission related interactions. The second section, examines the existing relevant literature and depicts the gap that has been left unfilled by earlier research. Also the intent and the aims of this paper are specified. The third section, refers to the methodological approach that was developed by the research relating to this paper, which particularly includes adjustment of the BBNs to the already introduced research problem. The fourth and the fifth sections, depict a case 
scenario as well as the compilation and organisation of data. In these sections, the associated findings of the scenario are introduced and discussed in detail. Different possible scenarios are also established and explained. In the sixth section, a brief conclusion is given and recommendations for future research are outlined.

\section{Literature Review}

Pursuing the energy efficiency of ship operations, the management approach of the ship-owner and the type of charter party contract that determines the operational responsibilities are crucial. Parker, Raucci, and Smith (2015) observed that the specific nature of the charter contract as well as the capacity and dimensioning of a vessel have significant influence on the Energy Efficiency Operational Index (EEOI) ratings. They highlighted that owner-operated ships are likely to achieve further efficient EEOI scores than time-chartered vessels due to the on-time transport requirement and the penalties included in the contract. In a more detailed study, Adland et al. (2017) investigated the energy efficiency of dry bulk ships operating under time charter by considering key macro, ship specific and contract specific variables. Their research found that the current market charter rates were significant factors in the effectiveness of energy efficiency measure. They determined that the vessel's age, bunker prices, place of delivery and DWT (Deadweight Tonnage) were also important factors across all ship sizes. In another study, Arslan, Besikci, and Olcer (2014) showed that, for particular ship types operated under specific contract terms, the reduction of the redundant times in ballast voyage and ports operations, and the increase of payload played a significant part in obtaining higher EEOI ratings.

Measuring the IEE of shipping operations does not employ a standardised methodological application for quantitative interpretations. In terms of data, surveillance and assessment of the detailed ship operation data has not yet been widely established in 
the industry (Banks 2015). By setting an aim for the IEE of shipping operations, Armstrong and Banks (2015) suggest that an array of measurement to enhance energy efficiency performance should be made accessible to the industry. These measurements ideally should comprise of enhancements concerning fleet scheduling, mirrored by weather routing applications, optimising speed and power; improved vessel operation profile including vessel trimming, ballasting and the refined use of navigation and effective cargo holding-handling equipment. In addition, a planned ship operation management which is explained as an effective administration of the goods to be loaded and discharged as well as a sophisticatedly arranged management of ship energy resources. On the other hand, there are researchers such as Jafarzadeh and Utne (2014), Rehmatulla and Smith (2015) and Johnson (2013) who suggest that there is an energy efficiency gap in the shipping industry due to various barriers. In order to overcome these barriers, they propose to implement practical energy efficiency measures such as operational measures like fuel consumption monitoring, weather routing, speed reduction or training. These studies also proved the need for a holistic approach to achieve a better IEE in shipping.

The optimisation of a voyage is a methodology to determine the best possible routeing for the carriers to raise the effectiveness of energy use and to diminish the emission of greenhouse gas emissions attributable to the maritime transport sector (Varelas et al. 2013). Aiming to implement these targets, Lu et al. (2015) employed a specific model based on "weather forecast data and multi-objective weightings" to identify an optimal energy efficient route for a particular ship's voyage. Their model considered also the building of a more efficient system by taking weather routing into account. In fact, focusing only the optimal route selection is not adequate to address the voyage optimisation problem. The compound nature of marine trade requires further 
advancements to consider the physical marine transport segment incorporated into the ship-port system. In another study, Cui, Turan, and Boulougouris (2016) developed a ship weather routing optimisation method taking both the arrival time and the fuel consumption into consideration. This model focused mostly on ship speed arrangement and engine performance for each available route option. However, the influences of the ship's time at port were not taking into account.

Ship voyage operations and the ship's port operations can be perceived as an integrated form to yield the maximum total efficiency (Windischhofer and Lepistö 2016). This could comprise of the investment in adequate (physical) resources to ensure an effective shore side operation equal to reliable communication, correspondence, collaboration and instrument resource monitoring between the concerned stakeholders (Banks, Turan and Incecik 2013). Additionally, Intertanko and OCIMF (2010) underlined that there is a significant volume of fuel lost from ships steaming ahead at full speed on account of mooring at port, although there are identified delays in port operation upon arrival. In order to avoid fuel inefficiencies, the vessel can bypass or minimise anchoring time by employing adaptive slow steaming and proper route planning. Thus, the GHG emissions and costs may be decreased, traffic of ships arriving can be avoided and safety can be advanced in the port berthing zones. It can also be argued that proper communication is a necessary component of the IEE due to the importance of clear and complete information exchange by the port operation stakeholders which effects the slow steaming and route selection decisions.

Looking the individual ship types, Starcrest Consulting Group (SCG 2009) highlighted that high inefficiency in energy consumption of container ships is observed on the trans-pacific line due to long port waiting times and high speed. For tanker shipping, Banks Turan and Incecik (2013) and Banks (2015) indicated that the bigger the 
tanker, the lesser waiting time is wasted in a port annually. This paper demonstrates that around $54 \%$ of the complete operation time for Handysize, $42 \%$ for Aframax and $32 \%$ for Suezmax tankers, is spend at the port during operation. Johnson and Styhre (2015) also suggested that it would be possible to improve the overall vessel energy effectiveness by reducing the time in ports. They focused on dry bulk transportation activities carried out in the North and Baltic Sea regions and they found that ships spend $40 \%$ of their total time at ports. They also described more than half of this time as "unproductive time". Their results showed that by reducing port time by around 4 hours, it would be possible to reduce energy consumption by between $2 \%$ and $8 \%$ depending on the ship's characteristics.

In order to study the ship-to-port interface and interoperability, essential parameters include time management, ship's operating profile and port's efficiency. Ferrari and Parola Tie (2015) investigated the influences of slow steaming in main liner shipping services and they highlighted the importance of the link between port time and slow steaming decisions. Jia, Parakash, and Smith (2017) studied energy efficiency with slow steaming when a delay is known at port by applying virtual arrival policy. They used AIS (Automated Identification System) data to measure potential energy consumption and emissions. They found that $50 \%$ of ship waiting time at ports could be reduced by just-in-time arrival and this would provide significant cost savings and reduction of $\mathrm{CO}_{2}$ emissions. Woo and Moon (2014) investigated whether the reduction of the ship's operation speed provide environmental and cost benefits or not in real practice. Their results showed that slow steaming was in favour of emission reductions; however, it would be cost-effective only for a particular ship speed range. In another study, Moon and Woo (2014) discussed the support of high quality port operations to a ship's energy efficiency and emission reduction. They found that especially larger ships need to be very 
careful of their port time to increase energy efficiency and reduce GHG emissions. Corbett, Wang, and Winebrake (2009) studied the influence of fuel prices and taxation on $\mathrm{CO}_{2}$ emissions and cost effectiveness by employing optimal ship speed decisions. Their results showed that increasing fuel tax may lead to slow steaming. Therefore, it would be possible to reduce the cost of transportation and $\mathrm{CO}_{2}$ emissions significantly.

As a result of the literature review, it is seen that the availability of holistic energy efficiency applications is considerably limited within maritime transport, combining influences of port performance with ship operation performance (Armstrong and Banks 2015; Johnson and Styhre 2015; Moon and Woo, 2014). The IEE management between port and fleet necessitates comprehensive systematic examination (Canbulat, et al. 2018). Recently, Shi et al (2018) reviewed green shipping studies including both ship and port issues in the literature and the wide range of methodologies applied on this problem. However, in their review, it is seen that the probabilistic BBNs approach has not been applied to tackle this problem before. The gap in the literature directs the research to establish a BBNs application model towards IEE of shipping, considering influences of both port and ship operation performances on speed arrangement and route planning. Especially, the research focuses on inter-operability of different organisational structures concerning the ship-port interface to develop energy efficiency further holistic way. The major purposes relating the research paper presented herein are as follows:

- Utilising BBNs modelling to define relationships of the integrated port-ship co-ordination to describe the port-ship interaction nodes regarding the energy efficiency and $\mathrm{CO}_{2}$ emissions.

- Acquiring quantitative results and developing an interdependency structure so the overall energy efficiency improves in marine transport systems, inclusive of the ship's voyage and port operations performance. The mentioned structure may enhance the 
interoperability amid ship and port operations by making use of a probabilistic concept. A visual software application of this method may also assist in demonstrating the exact and comprehensive graphic representation of the model established. According to Tungkasthan, Jongsawat, and Poompuang (2010) "GeNIe" software is one of the most appropriate analytical tools to be applied to BBNs modelling.

- Enhancing the resource effectiveness by amalgamated coordination between port and ship sides.

- Applying the BBN's concept to evaluate and improve the energy and $\mathrm{CO}_{2}$ consumption of the integrated marine transport system.

\section{Methodology}

An application of inter-operability/ dependability examination on marine transport can be an analytical way of assisting commercial shipping to become more energy efficient and environmentally friendly. The BBNs provides this opportunity to understand interactions of very complex systems in a probabilistic manner (Neil, Littlewood, and Fenton, 1996; Yuqing and Tong, 2008, Sutrisnowati, Bae, and Park 2014). The ship-port interface model with BBNs regarding the energy efficiency interactions demonstrates interoperability by utilising interdependency of ship and port operations (Canbulat, et al. 2018). This model will also provide an integration between port and ship operations by considering various parameters including weather conditions, ship characteristics, primary engine efficiency and ship speed planning and port efficiency. This section of the paper is going to introduce the application of BBNs and adaptation of BBNs approach to ship-port interface regarding the energy efficiency and $\mathrm{CO}_{2}$ emission interactions. 


\subsection{Bayesian Belief Networks (BBNs)}

Bayesian Theorem (BT) applies the prior and the probability functions to address the background knowledge in reversing conditional probability observations. BT also includes a statistical inference technique called Bayesian Inference. This is a technique in statistical inference that aids BT to enhance the probability for a hypothesis based on increasing availability of information. BT theorem can be described as follows (Bedford and Cooke, 2001):

$\mathrm{X}$ partition is a group of independent and identically distributed events with unknown distribution $X_{1}, \ldots, X_{n} \subset n \subset \Omega$ like that $X_{i} \cap X_{j}=\varnothing$ whenever $i \neq j$, and $X_{1} \cup, \ldots, \cup X_{n} \subset n \subset \Omega, \Omega$ is a sample space is the set of all possible outcomes. Assuming that $\mathrm{Y}$ is an event and if it has $X_{1}, \ldots, X_{n}$ a partition, especially $\operatorname{Pr}(Y) \neq 0$ with $\operatorname{Pr}(Y)>0$. At that time,

$$
\operatorname{Pr}\left(X_{l} \mid Y\right)=\frac{\operatorname{Pr}\left(Y \mid X_{i}\right) \operatorname{Pr}\left(X_{i}\right)}{\sum_{j=1}^{n} \operatorname{Pr}\left(Y \mid X_{j}\right) \operatorname{Pr}\left(X_{j}\right)}
$$

By using the definition of conditional probability, we can write the following formula:

$$
\operatorname{Pr}\left(X_{l} \mid Y\right)=\frac{\operatorname{Pr}\left(Y \mid X_{i}\right) \operatorname{Pr}\left(X_{i}\right)}{\operatorname{Pr}(Y)}
$$

The evidence of aforementioned description regarding conditional probability be able to states as undermentioned:

$$
\operatorname{Pr}(Y)=\sum_{j=1}^{n} \operatorname{Pr}\left(Y \cap X_{j}\right)
$$


It continues to extend the $\operatorname{Pr}(Y)$ term. Law of Total Probability states undermentioned:

$$
\operatorname{Pr}(Y)=\sum_{j=1}^{n} \operatorname{Pr}\left(Y \mid X_{j}\right) P\left(X_{j}\right)
$$

Where:

- $\operatorname{Pr}\left(X_{j}\right)$, the initial probability is named as the prior probability.

- $\operatorname{Pr}\left(X_{i} \mid Y\right)$, the updated probability is named as the posterior probability.

- $\operatorname{Pr}\left(Y \mid X_{i}\right)$ is named as the likelihood.

$\operatorname{Pr}(X i \mid Y)$ the probability of $Y$ given $X$ is formulated in equation 5 .

$$
\operatorname{Pr}\left(X_{l} \mid Y\right)=\operatorname{Pr}\left(Y \mid X_{i}\right) P\left(X_{l}\right)
$$

Then $1 / \sum_{j=1}^{n} \operatorname{Pr}\left(Y \mid X_{j}\right) P\left(X_{j}\right) \quad$ is the constant of proportionality required to ensure that the total probability equals 1 .

The BBNs can be defined as a graphic modelling method. It presents directed acyclic graph (DAG) in which the network nodes characterise stochastic variables (Yuan and Druzdzell 2006). Moreover, the relations between nodes are directed with arrows or arcs to represent probabilistic dependences.

The BBNs enciphers the distribution of joint probability between a set of variables $\left\{\mathrm{X}_{\mathrm{i}}, \ldots, \mathrm{X}_{\mathrm{n}}\right\}$ where $\mathrm{n}$ is subject to limitations and divides it into an outcome of dependent probability distributions across all individual variables connected to its parent nodes. In the case of nodes with parents, the prior probability is practiced. The joint probability distribution across $\left\{\mathrm{X}_{\mathrm{i}}, \ldots, \mathrm{X}_{\mathrm{n}}\right\}$ can be attained by using the output of each of these priors where; $\left\{\mathrm{X}_{\mathrm{i}}, \ldots, \mathrm{X}_{\mathrm{n}}\right\}$ where $\mathrm{n}$ is finite and divides it into an outcome of dependent 
probability distributions through all individual variable appoint its parents. When nodes obtain parents, the prior probability is computed. The distribution of joint likelihood across $\left\{\mathrm{X}_{\mathrm{i}}, \ldots, \mathrm{X}_{\mathrm{n}}\right\}$ can be performed by utilising the outcome of every single prior where;

$$
\operatorname{Pr}\left(X_{i}, \ldots, X_{n}\right)=\prod_{i=1}^{n} \operatorname{Pr}\left(X_{i} \mid P\left(X_{i}\right)\right)
$$

\subsection{Stages to apply the BBNs model}

A usual BBNs model requires four major steps to be followed (Cao, Coutts, and Lui 2013). Creating a Causal Concept Map (CCM) is a significant first step before transforming the CCM to structure of a BBNs Model (step 2). Then computation of the conditional probabilities need to be completed (step 3) before analysing the results of the BBNs (step 4). As it is illustrated in Figure 1, in this study developed 16 processes were developed to cover these four major steps. This detailed model requires mainly the structure nodes and connections for developing CCM. The BBNs connected by an arc are regularly named parent or child, subject to the arc direction.

\section{[Figure 1 near here]}

The BBNs method gives the flexibility of using a variety of data sources and knowledge which include small or incomplete datasets and specialist's knowledge (Uusitalo 2007). As illustrated in Figure 1, nodes of BBNs may adapt to remove the data subject to the thoughts of the experts in the stages. Therefore, changes on data set with experts' touch may have influence on probability distributions. However, the BBNs helps to use all available or accessible data to obtain the probabilities.

The BNNs is applicable to visually analyse inter-operability and interdependencies among defined integrated shipping energy efficiency system nodes. In this study, the GeNIe Modeller software tool is utilised to provide visual illustration of BBNs and mathematical calculation results (GeNIe Modeler 2017). 


\subsection{The BBNs model of the IEE of ship-port interface}

By applying BBNs methodology on ship-port interface regarding the energy consumption and $\mathrm{CO}_{2}$ emissions, the interoperability framework of systems is established. Expert opinions are utilised in the identification and development of parentchild hierarchy relationships of the nodes. According to the model developed in this study, port performance consists of port operation performance, port traffic and weatherrelated conditions. On the other hand, ship operation performance consists of ship resistance, and machineries and related systems performance. Based on the model, port and ship's operational performance outcomes influence slow steaming and route planning decisions which in turn also influence energy consumption and $\mathrm{CO}_{2}$ emissions. This methodological adaptation provides significant benefits for the industrial practices including:

- To identify energy efficiency interdependencies of ship and port operations.

- To clarify parameters influencing ship speed arrangement and route planning in a more holistic way, considering both ship and port aspects.

- To measure energy efficiency performance of a ship working on liner service, time charter on a specific voyage, or consecutive voyage charter between two ports.

- To know where to improve the performances of nodes based on different scenarios in order to get best outcomes.

When the following chart presented in Figure 1 is applied to create BBNs model, the visual illustration of the developed BBNs model application is developed as shown in Figure 2. To create better understanding of methodology and reduce the complexity for 
this first application, it is assumed that each of these variables in the BBNs are designed for 2 or 3 different states in the study.

\section{[Figure 2 near here]}

In order to clarify the node hierarchy of the developed BBNs model in Figure 2, the following part provides detailed explanation:

- Weather Condition (WC) refers to the weather condition of the actual simulated voyage of the ship which is attained from historical weather data. Probabilistic distribution of the recorded data is considered and divided into three sea state categories. They are taken into account based on Beaufort Numbers 0-3, 4-6, and $7-12$.

- Port Operation Performance (PO) refers to the discharging port performance. It is measured according to Expert Views based on specific case port for specific ship operation. 'Mean Value` indicates the port operation performance average for similar ships based on internet based commercial data statistics.

- Port Traffic (PT) refers to the existence of queuing density of the particular time based on marine traffic data. This section is divided into 2 stages; 'Busy` or 'Not Busy' to understand the queue in the port for that particular time.

- Loading Conditions ( $L C$ ) refers to the difficulty of the loading or unloading conditions at port. This is mainly caused by operational uncertainties which may occur due to the frequency of operational disruption. . "Moderate_Lower Difficulties" or "Heavy_Difficulties" are used as stages based on the perspective of experts within this field.

- Ship Resistance (SR) indicates the total resistance of the loaded ship including the weather influence. It is computed according to study of Y. J. Kwon and R. 
Lotensin theory cited in Kwon (2008). "Higher_Mean" or "Lower_Mean" are used by taking account of expert knowledge.

- Machineries and Related System Performance (MP): The efficiency of machinery components, including the shaft, based on current ship data. "Higher _Mean" or "Lower_Mean" are used as stages. The 'Mean Value' is computed regarding the research of Shao (2013) and Cui (2018), which calculate the mean of sea trail performance.

- Port Performance (SP): Performance of the entire port operation with various aspects generated according to existing port studies. "Higher_Mean (hm)" or “Lower_Mean (lm)" used as stages. The 'Mean Value' is taken based on port performance data of internet based commercial data statistics.

- Ship Operation Performance (SO): This indicates the performance of the ship based only on actual data regarding energy consumption. The 'Mean Value' is computed as the mean of the sea trail energy consumption concerning the study by Shao (2013).

- Route Planning (RP): Possible efficient route options are vital here and "Fuel_Efficient_Route" or "Not_Fuel_Efficient_Route" are used as stages. Data of the research of Cui (2018) is used as reference data.

- Ship Speed Arrangement (SS): The entire energy utilisation of the vessel regarding current vessel data and the study of Cui (2018) are used as reference calculation. "Slow_Steaming_Speed" or "Other_Speed" are used as stages.

- Energy Consumption (EC): The entire energy utilisation of the vessel established on current ship data and calculations based on research by Cui (2018) "Higher_Mean (hm)" or “Lower_Mean (lm)" are used as stages. The 
'Mean Value' refers to the average energy consumption of the possible scenarios of the ship energy consumption.

- $\mathrm{CO}_{2}(\mathrm{CO})$ : Total $\mathrm{CO}_{2}$ emission of the ship based on existing ship data and ship consumption calculation based on ship trial data. Only the ship energy consumption is considered. "Higher_Mean" or "Lower_ Mean" are used as stages.

- (Port) Storage Performance (SP): Performance of the port storage system is used for analysis. Due to the lack of port data availability, the commercial data statistics is also used together with expert views.

- Equipment Performance (EP): Performance of port equipment based on existing port terminal handling equipment. Due to the lack of available data, only port equipment performance is considered. User performances are excluded.

- Land Logistic Performance (LL): Performance of land logistic based on expert's views are used.

- Main Engines (ME): Performance of the main engine of the vessel by using recorded vessel data. The 'Mean Value' is computed as the mean of the sea trail capability established on specialist knowledge by taking in to account the research from Shao (2013).

- Auxiliary Engines ( $A E$ ): Similarly to primary Engine, the auxiliary engine performance of the ship according to recorded vessel data is used. The 'Mean Value' is calculated as the mean of the computed sea trial performance drives expert knowledge by taking in to account the research from Shao (2013).

Every node requires a probability table in the BBNs model. These tables can have conditions on the situations of their parental nodes or marginal over the states if the node has not had any parental nodes. This is usually needed to perform parameterisation of the 
model by use of conditional probability tables (CPTs), which are determined by utilising data or any other available facts regarding the case or issue, expert opinion or real data sets. CPT tables are illustrated in Figure 3 as part of the model.

Each CPT is represented by conditional probabilities $\operatorname{Pr}(\mathrm{X} \mid \mathrm{Y})$, where; $\mathrm{X}$ is the child node and $\mathrm{Y}$ is the parent node. In the BBNs probability allocation, the outcome of the conditional probabilities of all individual variables of a node is established only on its parental nodes.

This characteristic of BNs explains that all marginal prior and posterior probabilities can be acquired by marginalizing and conditioning. Thus, an understanding about one or more variables can be amended as new knowledge or proof about other variables is gained.

\section{[Figure 3 near here]}

After development of the BBNs model the formula of the Energy consumption calculation under condition lower mean consumption $(\mathrm{lm})$ of $(\mathrm{EC})$ can be given as shown in equation 7 by using GeNIe:

$$
\begin{aligned}
& \operatorname{Pr}(E C=l m)=\sum_{P P, S O, R P, S S} P\left(P P=p p_{i}, S O=s o_{i}, R P=r p_{i}, S S=s s_{i} E C=l m\right)=P(P P= \\
& h m, S O=h m, R P=f e, S S=o s, E C=l m)+P(P P=h m, S O=h m, R P=f e, S S=s s, E C=l m)+ \\
& P(P P=h m, S O=h m, R P=n f, S S=o s, E C=l m)+P(P P=h m, S O=l m, R P=f e, S S= \\
& o s, E C=l m)+P(P P=l m, S O=h m, R P=f e, S S=o s, E C=l m)+P(P P=h m, S O=h m, R P= \\
& n f, S S=s s, E C=l m)+P(P P=h m, S O=l m, R P=f e, S S=s s, E C=l m)+P(P P=l m, S O= \\
& h m, R P=f e, S S=s S, E C=l m)+P(P P=h m, S O=l m, R P=n f, S S=o s, E C=l m)+P(P P= \\
& l m, S O=h m, R P=n f, S S=o s, E C=l m)+P(P P=l m, S O=l m, R P=f e, S S=o s, E C=l m)+ \\
& P(P P=h m, S O=l m, R P=n f, S S=s S, E C=l m)+P(P P=l m, S O=h m, R P=n f, S S= \\
& s s, E C=l m)+P(P P=l m, S O=l m, R P=f e, S S=s s, E C=l m)+P(P P=l m, S O=l m, R P= \\
& n f, S S=o s, E C=l m)+P(P P=l m, S O=l m, R P=n f, S S=s S, E C=l m)
\end{aligned}
$$


Where:

- EC: Energy Consumption

- PP: Port Performance

- RP: Route Planning

- SO: Ship Operation Performance

- SS: Ship Speed Arrangement

- hm: Higher Mean

- Im: Lower Mean

The following formula shows EC under the condition, which has higher probability than a mean value $(\mathrm{hm})$ of a typical operation:

$$
\operatorname{Pr}(E C=h m)=(1-\operatorname{Pr}(E C=l m)
$$

\section{Case Study}

Within this case study, data of a $35,600 \mathrm{DWT}$ Bulk Carrier is gathered to implement a simplified model, evolved with BBNs. Some vessel specifications are illustrated in Table 1. The Port of New York (USNYC) and the Port of Southampton (GBSOU), one of the major ports within the UK, have been respectively selected as the outward and inward ports for this case study. A map illustration of the voyage is shown in Figure 4. Departure day from USNYC is 01.05.2014 and arrival day in GBSOU is 10.05.2014.

[Table 1 near here]

[Figure 4 near here] 
The quantitative hierarchal probabilistic interactions between the variables of the case study are illustrated thanks to the facilitation of the Bayesian network. By implementing the stages of the BBNs practice, as thoroughly described in the preceding section, it is possible to display each variable as a node. The energy efficiency interface between the port and ship following the implementation of a BBNs model is indicated within Figure 5. The distinct format (nodes and interconnections) of the model is evolve from existing research and specialist opinions (Hansen 2012). The joint probability distribution of the considered variables is exhibited analytically in the BBNs model. The data highlighted in Table 2 has been utilised to consider the precise distribution of the probabilistic independencies amidst the modelled nodes. All nodes are individually characterised by a conditional probability interaction on its parent node. For example, the nodes given in Figure 5 illustrate all CBTs by the prior probability interactions across results displayed in Table 2. The Node 'Loading Conditions' was depicted by a likelihood distribution over its results (Low/Moderate Traffic and Heavy Traffic), and its contingent relationship on the results of its parent node (hub Weather Condition, results 0-3, 4-6, and 7-12). Specialist judgement assisted to evoke the structure and numerical parameters of the BBNs model. As outlined in Table 2, the data was obtained from operational measurements including data from ships and ports, recorded meteorological data, as well as previously published data. The study by Cui, Turan, and Boulougouris (2016) assisted in calculating the CPTs of route planning and energy consumption nodes, using optimum route data with minimum fuel consumption for this case study. Data which was publicly available was utilised to obtain port weather condition data (Wunder 2016).

[Figure 5 near here]

[Table 2 near here] 


\section{Results and Discussion}

The results are generated by applying the GeNIe version 2.1 for the chosen case after applying the model of BBNs. Final outcomes are shown in Figure 6 as a value of nodes` outcome for Energy Consumption and $\mathrm{CO}_{2}$. The model application of this integrated system is expected to be energy efficient by $58 \%$ and $\mathrm{CO}_{2}$ efficient by $61 \%$ respectively in comparison to mean of previous recorded data when we consider them as indicator.

\section{[Figure 6 near here]}

On the other hand, there is still higher probability of having lower energy consumption than the average performance, in comparison to similar ship voyages and port operations. When exact information about higher port performance than the mean value is known, the ship has better energy efficiency probability, in comparison to results previously given in Figure 7. Similarly, when the ship operation performance is predicted to be higher than the mean value, relating to energy efficiency, the likelihood of being $\mathrm{CO}_{2}$ and energy efficient rapidly increases, as displayed in Figure 8.

\section{[Figure 7 near here]}

\section{[Figure 8 near here]}

Assuming the ideal ship operation performance, the likelihood of consuming less energy, in comparison to the mean value, rises from $58 \%$ to $86 \%$. Likewise, the possibility of less $\mathrm{CO}_{2}$ emission, in comparison to the mean value, increases from $61 \%$ to $85 \%$. The result primarily determines that positive adjustments in ship operation related nodes have a greater impact on energy consumption and $\mathrm{CO}_{2}$ emission than port-related ones. However, both port performance and ship operation needed to be coordinated to reach 
the possibility of having $100 \%$ energy and $\mathrm{CO}_{2}$ efficient system in comparison to previously recorded data of ship working on time charter or consecutive voyage charter. It certainly clarifies that the port performance and ship operation performance complete each other to run a much better energy efficient operation.

Table 3 illustrates the results of each states under 6 different assumptions and actual situations. These results not only give an opportunity to compare the impact of each scenario, but also provide the possibility to analyse the impact of each node on others. For instance, cooperation between real results and scenario 1 illustrates that some improvements needed to be carried out to reach a complete energy and $\mathrm{CO}_{2}$ efficient operation. Some possible actions are required to increase the level of the performances e.g. machinery performance needs to increase by $9 \%$, and main engine and port performance need to increase by $8 \%$. In addition, the table demonstrates that there is a big gap between scenario 1 and real results. However, this gap indicates the possible probabilistic limits of efficient system and differences between these two situations. To be able to reach $100 \%$ port efficiency, some vital developments are required for enhanced port operation performance. It should be enhanced by $27 \%$ and some minor variations should be made for port berthing traffic by $5 \%$ without any change of loading conditions.

Scenario 2 represents the worst state as the absolute value of not being an energy and $\mathrm{CO}_{2}$ efficient system. The impact of the port performance on results when the port performance is known exactly is lower than the mean value. It increases the $\mathrm{CO}_{2}$ emission by $19 \%$ and energy consumption by $13 \%$ without any change to ship engine or resistance.

Table 3 provides the detailed results for scenario 4 and 5 for the same assumptions made in figure 7 and figure 8 with regards to port and ship operation performances which are higher than the average values. Table 3 also shows the results for scenarios 6 and 7 for the opposite assumptions with regards to port and ship operation performances, which 
are lower than the average values. The comparison of these last 4 scenarios emphasise that $\mathrm{CO}_{2}$ consumption decreases much slower than the energy consumption declines when performance of port activities is improved. Moreover, these results show that slight changes create a vital impact on the same nodes when any of the certain values are changed by conditional probability.

\section{[Table 3 near here]}

\section{Conclusion}

This research introduced a methodological framework to demonstrate the influence of integrated ship-port operations regarding ship energy efficiency. The methodology is in line with BBNs on the ship-port interface by utilising the interdependencies among port and ship operations in terms of ship's energy consumption and $\mathrm{CO}_{2}$ emissions. Therefore, by establishing an inter-operability link between ship voyage and port operation aspects, a more holistic and integrated way of operational energy efficiency performance measure is generated.

In this paper, different research efforts including port operation, weather routing and slow steaming studies were integrated under one probabilistic methodology. The Port-ship integration energy efficiency framework was established based on the conditional probability theory and was practically applied on the given case study. The case application of the study also gave a chance to understand the probabilistic relation between all nodes in practice. Therefore, the results of different scenarios show that the IEE may be achievable with some improvements in different nodes. Each of the possible assumption results gives a chance to understand the impact of these potential changes on the IEE of ship-port interface 
This research has the potential to build more understanding and create more opportunities around the idea of probabilistic modelling, with the aim of enhancing energy efficiency for specific operations for a range of ship types. The findings of this paper have a number of important implications for future practice. Firstly, it will be possible to develop a commercial software application with coding based on probabilistic BBNs methodology. Furthermore, the study may create opportunities for the publication of new studies on self-organisation of port operations to adapt to the changing energy efficiency requirements regarding vessels. Moreover, this research offers to quantity the IEE of ship operation and to determine and eliminate barriers causing an energy efficiency gap. Lastly, new understanding of this research will generate the application of similar methodologies in different engineering and operation management problems where efficiency with interoperability is needed.

\section{Acknowledgement}

The authors would like to thank the National Education Ministry of Turkey for their financial support. In addition, we extend our thanks to Dr Mingyu Kim, Dr Tong Cui, Mr Dogancan Uzun, Alexander Senss for their assistance and comments which helped to greatly improve the manuscript. Mr Canbulat work was supported from National Education Ministry of Turkey. Dr. Boulougouris work was supported from DNVGL and RCCL, sponsors of the MSRC. The opinions expressed herein are those of the authors and do not reflect the views of DNVGL and RCCL. 


\section{References}

Adland, R, H. Alger, J. Banyte, and H. Jia. 2017. "Does Fuel Efficiency Pay? Empirical Evidence from the Drybulk Timecharter Market Revisited." Transportation Research A, 95: 1-12

Armstrong, VN., and C. Banks. 2015. "Integrated approach to vessel energy efficiency." Ocean Engineering J 110: 39-48

Arslan, O, E. Besikci, A. Olcer. 2014. Improving Energy Efficiency of Ships through Optimisation of Ship Operations. Theme: Sustainable modern shipping technologies. No. FY2014-3 IAMU. IAMU. Malmo, Sweden

Banks, C., O., Turan, and A., Incecik. 2013. Understanding ship operating profiles with an aim to improve energy efficient ship operations. In Proceedings of the Low Carbon Shipping Conference, London

Banks, Charlotte. 2015. “Operational practices to improve ship energy efficiency”. PhD diss., University of Strathclyde.

Bedford, T., and R. Cooke. 2001. Probabilistic risk analysis: foundations and methods. Cambridge. Univ. Press, UK.

Buxton, I. 1985. "Fuel costs and their relationships with capital and operating costs." Maritime Policy and Management J 12(1): 47-54.

Canbulat, O., M. Aymelek, O. Turan, and E. Boulougouris. 2018. A Bayesian Belief Network Model for Integrated Energy Efficiency of Shipping. In Trends and Challenges in Maritime Energy Management, 257-273. Springer, Cham.

Cao, T., A. Coutts, and FA. Lui. 2013. "Combined Bayesian Belief Network Analysis and Systems Architectural Approach to analyse an Amphibious C4ISR System”. National Conference of the Australian Society for Operations Research, Adelaide, December 1-6.

Corbett, J. J., H. Wang, and J. J. Winebrake. 2009. “The Effectiveness and Cost of Speed Reductions on Emissions form International Shipping." Transportation Research Part D, 14: 593-598

Cui, T., O. Turan, and E. Boulougouris. 2016. "Development of a ship weather routing system for energy efficient shipping”. Paper presented at the Annual conference of the International Association of Maritime Economists, Hamburg. August 26.

Cui, Tong. 2018. "Development of a Ship Weather Routing System towards Energy Efficiency of Shipping.” PhD Diss., University of Strathclyde. 
Cullinane, Kevin. 2014. Targeting the Environmental Sustainability of European Shipping: The Need for Innovation in Policy and Technology. Report no 6. EPSD - European Panel of

Ferrari, C., and F. A. Parola Tei. 2015. "Determinants of Slow Steaming and Implications on Sevice Patterns." Maritime Policy and Management, 42(7): 636-652

GeNIe Modeler. 2017. "GeNIe Modeler User Manual” Accessed 17 May 2017. http://support.bayesfusion.com/docs/genie.pdf.

Hansen, Søren Vinther. 2012. "Performance monitoring of ships" PhD diss., Technical University of Denmark.

Helfre, J. F., P. A. C. Boot. 2013. Emission reduction in the shipping industry: Regulations, exposure and solutions.

Hesar, A. S. 2013. "Structure learning of Bayesian belief networks using simulated annealing algorithm.” Middle-East Journal of Scientific Research, 18(9): 13431348.

IMO. 2014. Third IMO Greenhouse Gas Study 2014. International Maritime Organization, 327. London, UK

Intertanko, and OCIMF. 2010. Virtual Arrival, Optimising voyage management and reducing vessel. Oil Companies International Marine Forum, United Kingdom.

Jafarzadeh, S., and I. B. Utne, 2014. "A framework to bridge the energy efficiency gap in shipping." Energy 69(0), 603-612.

Jia H., R. Adland, V. Parakash, and T. Smith. 2017. "Energy Efficiency with the Application of Virtual Arrival Policy." Transportation Research Part D: Transport and Environment, 57: 50-60

Johnson, H. 2014. GHG Emissions and the Energy Efficiency Gap in Shipping. European Panel of Sustainable Development.

Johnson, H., and L. Styhre. 2015. "Increased Energy Efficiency in Short Sea Shipping through Decreased Time in Port." Transportation Research A. 71: 167-178

Johnson, Hannes. 2013. "Towards understanding energy efficiency in shipping, Department of Shipping, Division of Maritime Operations.” Bachelor Degree Diss. Chalmers University of Technology, Goteborg.

Kwon, Y. J. 2008. "Speed loss due to added resistance in wind and waves." The Naval Architect, RINA U K. March. 
Lee, T., and H. Nam. 2017. "A Study on Green Shipping in Major Countries: In the View of Shipyards, Shipping Companies, Ports and Policies." The Asian Journal of Shipping and Logistics, 33: 253-262

Lu, R., O. Turan, E. Boulougouris, and C. Banks. 2015. "A semi-empirical ship operational performance prediction model for voyage optimization towards energy efficient shipping." Ocean Engineering J. 1; 110: 18-28.

McKinnon, Alan C. 2014. "Options for Reducing Logistics-Related Emissions from Global Value Chains.” Robert Schuman Centre for Advanced Studies Research Paper No. RSCAS 2014/31. Available at SSRN: https://ssrn.com/abstract=2422406

Moon, D. S. H., and J. K. Woo. 2014. "The impact of port operations on efficient ship operation from both economic and environmental perspectives." Maritime Policy and Management, 41(5): 444-461

Neil, M. B., Littlewood, N. Fenton. 1996. Applying Bayesian belief networks to system dependability assessment. InSafety-Critical Systems: The Convergence of High Tech and Human Factors. Springer. London.

Ozturk, E. 2013. “Operational Measures for Energy Efficiency in Shipping.” Journal of ETA Maritime Science, 1 (2): 65-72

Parker, S., C. Raucci, and T. W. P. Smith. 2015. Understanding the Energy Efficiency Operational Indicator: An empirical analysis of ships from the Royal Belgian Shipowners' Association. Energy Institute. s.l. Royal Belgian Shipowners' association.

Plessas, T., A. Papanikolaou, M. Pytharoulis, E. Boulougouris, and N. Adamopoulos. 2013. Simulation of loading/discharging procedure of tankers. Developments in Maritime Transportation and Exploitation of Sea Resources: IMAM 2013. Guedes Soares, C. \& Lopez Pena, F. (eds.). London: CRC Press, 501-510.

Rehmatulla, N., and T. Smith. 2015. "Barriers to Energy Efficient and Low Carbon Shipping." Ocean Engineering, 110(B): 102-112

SCG. 2009. "2006 Expanded Greenhouse Gas Inventory.” Accessed January 172016. https://www.portoflosangeles.org/DOC/REPORT_GHG_Inventory_2006.pdf

Shao, Wei. 2013. "Development of an intelligent tool for energy efficient and low environment impact shipping." PhD diss., University of Strathclyde. 
Sharma, S. 2014. "Global Voyage Centre: energy efficiency and route optimisation." Accessed November 18 2014. http://maersklinesocial.com/global-voyage-centreenergy-efficiency-and-route-optimisation/\#sthash.Qz0BkOzJ.dpuf.

Shi, W., Y. Xiao, Z. Chen, H. McLaughlin, and H. K. Li. 2018. "Evolution of green shipping research: themes and methods.” Maritime Policy \& Management. 1-13

Sutrisnowati, R. A., H. Bae, and J. Park. 2014. "Bayesian Network Learning For PortLogistics-Process Knowledge Discovery." International Journal of Industrial Engineering. 1;21(3):141-52.

Tungkasthan, A., N. Jongsawat, and P. Poompuang 2010. "Automatically building diagnostic bayesian networks from on-line data sources and the smile web-based interface" INTECH Open Access Publisher.

Uusitalo, L. 2007. "Advantages and challenges of Bayesian networks in environmental modelling." Ecological modelling. 10; 203 (3): 312-8.

Varelas, T, S. Archontaki, J. Dimotikalis, O. Turan, I. Lazakis, and O. Varelas. 2013. Optimizing ship routing to maximize fleet revenue at Danaos. INFORMS Journal on Applied Analytics. 43(1): 37-47.

Windischhofer, R., and M. Lepistö. 2016. "Integrated Operations: ABB's digital business transformation for the maritime industry." Accessed February 172017. http://new.abb.com/marine/generations/technical-insight/integrated-operations.

Winnes, H., L. Styhre, and E. Fridell. 2015. "Reducing GHG Emissions from Ships in Port Areas." Research in Transportation Business \& Management. 17(2015): 7382.

Woo J-K., and D. S-H. Moon 2014. "The Effects of Slow Steaming on the Environmental Performance of Liner Shipping." Maritime Policy \& Management, 41(2): 176191

Wunder G. 2016. Historical Weather. Accessed January 172017. https://www.wunderground.com/history/.

Yuan C., and MJ. Druzdzel. 2006. "Importance sampling algorithms for Bayesian networks: Principles and performance." Mathematical and Computer Modelling. 2006;43(9):1189-207.

Yuqing L., Z. Tong. 2008. "Bayesian Network to Construct Interoperability Model of Open Source Software.” InComputer Science and Software Engineering. 3:758761, IEEE. Hubei. 